\title{
Breve análise da importância dos órgãos executores da política ambiental brasileira frente aos agravos ambientais em unidades de conservação
}

\section{Patrício Rinaldo dos Santos ${ }^{1}$, Valdilene Valdice de Santana ${ }^{1}$, Michelle Cristina Varela dos Santos ${ }^{2}$ e Valdemir dos Santos Lopes ${ }^{3}$}

\begin{abstract}
${ }^{1}$ Universidade Federal de Pernambuco. Programa Regional de Pós-Graduação em Desenvolvimento e Meio Ambiente (PRODEMA/UFPE). Centro de Filosofia e Ciências Humanas. Av. Prof. Moraes Rego, 1235. Cidade Universitária. Recife-PE, Brasil (CEP 50670-901). E-mail: patricioibimirim@hotmail.com.

${ }^{2}$ Universidade Federal do Rio Grande do Norte. Programa Regional de PósGraduação em Desenvolvimento e Meio Ambiente (PRODEMA/UFRN). Centro de Biociências. Av. Sen. Salgado Filho, 3000. Candelária. Natal-RN, Brasil (CEP 59072-970).

${ }^{3}$ Universidade Federal de Pernambuco. Centro de Filosofia e Ciências Humanas. Departamento de Ciências Geográficas (DCG/UFPE). Av. Prof. Moraes Rego, 1235. Cidade Universitária. Recife-PE, Brasil. (CEP 50670-901).
\end{abstract}

Resumo. Objetivamos com este trabalho descrever a importância das unidades de conservação (UCs) para a preservação dos recursos naturais no Brasil e competências desempenhadas pelos órgãos executores da Política Nacional de Meio Ambiente (PNMA) junto a esses espaços especialmente protegidos. As unidades de conservação são ambientes notadamente tutelados pela legislação ambiental brasileira, em especial pela Lei $\mathrm{n}^{\circ}$ 9.985/2000, que instituiu o Sistema Nacional de Unidades de Conservação (SNUC), cuja historicidade tem fundamento em normatizações significativas como o antigo Código Florestal de 1934. O advento da Lei $\mathrm{n}$ - $11.516 / 2007$ institucionalizou o controle e fiscalização das UCs como sendo de competência do ICMBio, bem como exercer o poder de polícia ambiental, executar ações da política nacional de unidades de conservação da natureza, e dentre outras. Os serviços prestados por estes entes fiscalizatórios IBAMA e ICMBio, respectivamente, são de extrema

Recebido 05/02/2020

Aceito

$21 / 04 / 2020$

Disponível on line

$22 / 04 / 2020$

Publicado

$30 / 04 / 2020$

Acesso aberto acuidade para implemento dos atos de inspeção e gestão das unidades de conservação, sendo imperativo a continuidade da admissão e permanência de autonomia dos órgãos executores da Política Nacional do Meio Ambiente (PNMA) para manutenção dos recursos ambientais e qualidade de vida.

ISSN 2359-1412/RBGAS-2020-0015/2020/7/15/15/211

Rev. Bras. Gest. Amb. Sustent.

http://revista.ecogestaobrasil.net 
Palavras-chave: Sustentabilidade; Unidades de conservação; Política Nacional do Meio Ambiente; Órgãos executores; Fiscalização.

\begin{abstract}
Brief analysis of the importance of the executing agencies of the Brazilian environmental policy in view of the environmental problems in protected areas. With this work, we aim to describe the importance of conservation units for the preservation of natural resources in Brazil and competencies performed by the executing bodies of the National Environment Policy (PNMA) with these specially protected spaces. Conservation Units are environments notably protected by Brazilian environmental legislation, in particular Law 9,985/2000, which established the National System of Conservation Units (SNUC), whose historicity is based on significant standardizations such as the ancient Brazilian Forest Code of 1934. The advent of Law 11,516/2007 have institutionalized control and supervision in CCs as being the competence of ICMBio, as well as exercising the power of environmental police, executing actions of the national policy of nature conservation units, and among others. The services provided by these IBAMA and ICMBio supervisory entities, respectively, are extremely acuity to implement the acts of inspection and management of conservation units, and it is imperative the continuity of the admission and permanence of autonomy of the executing bodies of the National Environment Policy for the maintenance of environmental resources and quality of life.
\end{abstract}

Keywords: Sustainability; Conservation units; National Environment Policy; Executing agences; Surveillance.

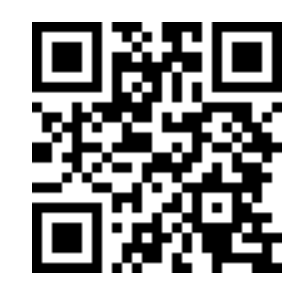

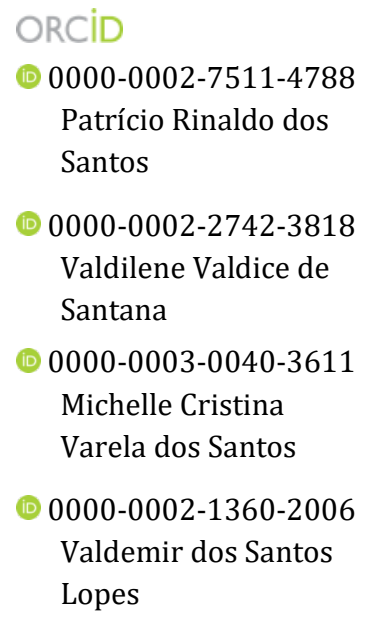

\section{Introdução}

O presente artigo em evidência traz uma reflexão sucinta sobre a importância das unidades de conservação (UCs) para a conservação e preservação dos recursos naturais essenciais para manutenção da qualidade de vida dos seres viventes em superfície terrestre, especialmente em território brasileiro. Além disso, exibe aspectos conceituais e característicos de unidades de conservação extremamente viáveis em dias atuais para preencher os pré-requisitos e desígnios de preservação da biodiversidade em jurisdição soberana e internacional.

Em seguida, ao longo deste estudo elucidamos as normatizações que involucram a matéria unidades de conservação na legislação ambiental brasileira, origem e competências dos órgãos executores da Política Nacional de Meio Ambiente (PNMA), Lei no 6.938/1981, frente aos malefícios provocados ao meio ambiente ecologicamente equilibrado. 0 presente estudo justifica-se em virtude da observância das atitudes e atividades antrópicas demasiadas efetuadas em desacordo com as doutrinas jurídicas na esfera ambiental nacional, a qual se considera como uma das mais evoluídas do mundo. Recentemente as eras foram marcadas por sérios agravos e impactos negativos ocasionados ao meio ambiente em razão da falta de responsabilidade e cuidados dos seres humanos. 
Os anseios pelo crescimento econômico a qualquer custo em diversos aspectos impulsionam os governos de países em processo de desenvolvimento como o Brasil a adotar práticas adversas ou em desarmonia com os objetivos e metas delineadas para o alcance da sustentabilidade. Processos modificadores de paisagens como o desmatamento, queimadas, expansão da fronteira agropecuária (implantação de atividades agrossilvipastoris), mineração, urbanização sem planejamento e controle, etc., contribui para o surgimento de problemas e catástrofes socioambientais como, por exemplo, enchentes, erosão, aparecimento de agentes, pragas e doenças, mudanças edafoclimáticas, etc. De acordo com Barros et al. (2012) estudos e trabalhos de Gestão Ambiental refletem a preocupação da humanidade, no que se refere à utilização dos recursos naturais, incluindo a necessidade da busca pela forma adequada de exploração, transformação e consumo, para que estas etapas sejam otimizadas e a exaustão seja evitada ou protelada por um longo prazo.

A política ambiental praticada em um país indica o modo como os recursos naturais são utilizados e adequados para o desenvolvimento de atividades econômicas que geram impactos potencialmente degradantes (Ferreira e Salles, 2016). Em virtude de tais implicações anteriormente reveladas foram criados os espaços especialmente protegidos, dentre eles as unidades de conservação (UCs) e seus respectivos "mandamos" ou regramentos jurídicos e órgãos gestores e protetivos como a exemplo dos órgãos de fiscalização federais o Instituto Brasileiro de Meio Ambiente e Recursos Naturais Renováveis (IBAMA) e o Instituto Chico Mendes de Conservação da Biodiversidade (ICMBio), órgãos executores da Política Nacional do Meio Ambiente (PNMA).

Deste modo, com base nas normatizações pertinentes e análises literárias sobre o tema em relevo, objetivou-se com este trabalho descrever a importância das unidades de conservação (UCs) para a preservação dos recursos naturais no Brasil e competências desempenhadas pelos órgãos executores da Política Nacional de Meio Ambiente (PNMA) junto aos espaços especialmente protegidos.

\section{Procedimento metodológico}

As pesquisas bibliográfica e documental embasaram os procedimentos técnicos que orientaram a elaboração deste artigo (Bezerra et al., 2018). 0 presente estudo em evidência é do tipo qualitativo pautado em estudos anteriores, como o de Madruga Filho et al. (2018). Para tanto, foram necessárias realização de cuidadosas consultas bibliográficas e documentais que norteiam o tema Unidades de Conservação, Política Nacional do Meio Ambiente e os órgãos responsáveis pela execução de tais atos de controle e fiscalização em áreas especialmente protegidas.

De acordo com Chizzotti (2003) o termo qualitativo implica uma partilha densa com pessoas, fatos e locais que constituem objetos de pesquisa para extrair desse convívio os significativos visíveis e latentes que somente são perceptíveis a uma atenção sensível. 0 estudo teve como fundamento o método dedutivo proposto por Tuan (1980), seguido por Rodrigues et al. (2010). 0 método dedutivo auxiliou nos trabalhos inerentes a pesquisa de cunho descritivo na qual foram realizadas consultas bibliográficas a legislação pertinente, artigos de periódicos, manuais, livros, monografias, dissertações e outros instrumentos de coleta de dados.

\section{Conciso panorama histórico das unidades de conservação (UCs) no Brasil}

As Unidades de Conservação no Brasil foram criadas a partir da década de 1930, com o intuito de, sobretudo, promover a conservação da biodiversidade, dos ecossistemas e das paisagens da ação predatória antrópica (Brasil, 2000). No Brasil os principais dispositivos de proteção da Natureza foram criados no início da década de 1930 
(Orzechowski e Liesenberg, 2009), com aparecimento legislativo e inovador do primeiro Código Florestal de 1934. Porém, a política de criação de áreas especialmente protegidas para a conservação da natureza tem como marco principal o ano de 1937, com a criação do Parque Nacional do Itatiaia (Franco et al., 2015; Milaré, 2009; Silva, 2016).

No entanto, a preocupação com as questões ambientais em nosso país tomou alento somente a partir de 1972, quando aconteceu em Estocolmo, na Suécia, a Conferência das Nações Unidas para o Meio Ambiente (Hüller e Mello, 2011). A Lei no 4.771/1965, por sua vez, já positivou a criação pelo Poder Público de Parques Nacionais, Estaduais e Municipais, Reservas Biológicas e Florestas Nacionais, Estaduais e Municipais (Brasil, 2000; Silva, 2016).

O Decreto no 23.793/1934, conhecido como o Código Florestal, tinha o objetivo de regulamentar, de forma mais abrangente, o uso de nossas florestas (Brasil, 1934), que, neste aspecto, foi bastante ineficiente, já se previa a criação de parques nacionais e áreas protegidas nas regiões Nordeste, Sul e Sudeste (Coutinho, 2005). Dessa forma, foram criados os primeiros 16 parques do país, entre os anos de 1934 e 1965, o que não implica dizer que, na época do império, não houve esboços de áreas preservadas determinadas pelo imperador (Silva, 2005; Silva e Cunha, 2010). Neste seguimento, a Lei no 6.938/1981 designou a Política Nacional do Meio Ambiente (PNMA) no intuito de atingir os seus objetivos e estabeleceu como um de seus 13 instrumentos basilares a criação de espaços territoriais especialmente protegidos pelo poder púbico federal, estadual e municipal, tais como áreas de proteção ambiental, de relevante interesse ecológico e reservas extrativistas.

Desde o seu delineamento, com a edição da Lei no 6.938/1981, a Política Nacional do Meio Ambiente (PNMA) apresentou como um dos seus sustentáculos a criação de espaços territoriais especialmente protegidos (Farias et al., 2016). Dentre as doutrinas editadas para este fim tem-se os artigos $2^{\circ}$, 4을 e 9o da referida Lei - PNMA, os quais salientam a importância da criação das áreas protegidas através dos incisos II, IV e VI respectivamente, a saber:

II - À definição de áreas prioritárias de ação governamental relativa à qualidade e ao equilíbrio ecológico, atendendo aos interesses da União, dos estados, do Distrito Federal, dos Territórios e dos Municípios;

[...]

IV - Proteção dos ecossistemas, com a preservação de áreas representativas;

\section{$[\cdots]$}

VI - A criação de espaços especialmente protegidos pelo Poder Público Federal,

Estadual e Municipal, tais como áreas de proteção ambiental, de relevante interesse ecológico e reservas extrativistas (Brasil, 1981).

Contudo, apenas com o advento da Carta Magna de 1988 a criação de espaços ambientalmente protegidos ganhou status constitucional, passando a constituir um dos principais instrumentos tanto da política nacional de meio ambiente, quanto da implementação do direito constitucional ao meio ambiente equilibrado (Silva, 2016). Sendo assim, para regulamentar o artigo 225 da Constituição de 1988, instituiu-se o SNUC, Lei no 9.985/2000, o qual dispõe sobre as unidades de conservação, definidas como sendo "espaço territorial e seus recursos ambientais, incluindo as águas jurisdicionais, com características naturais relevantes, legalmente instituído pelo Poder Público com objetivos de conservação e limites definidos, sob regime especial de administração ao qual se aplicam garantias adequadas de proteção" (Brasil, 2000; Silva e Cunha, 2010).

As unidades de conservação (UC) foram criadas com o intuito de proteção ambiental, nas esferas federal, estadual e municipal em todo o território brasileiro, a partir 
da instituição do Sistema Nacional de Unidades de Conservação da Natureza (SNUC), com a publicação da Lei no 9.985/2000 (Menezes, 2018). Milano et al. (1993) relatam que o Sistema de Unidades de Conservação deve comtemplar a conservação da diversidade biológica a longo prazo, centrando-a como eixo fundamental do processo conservacionista, além de estabelecer a necessária relação de complementariedade entre as diferentes categorias de unidades de conservação. Para atingir os objetivos propostos no SNUC, esta lei define duas categorias de unidades de conservação, as unidades de uso integral e as unidades de uso sustentável (Hüller e Mello, 2011).

As unidades de proteção integral foram criadas com o intuito de assegurar a preservação da Natureza, restringindo, desse modo, o uso de seus recursos de forma direta, ou seja, o uso que não envolve o consumo, coleta, dano ou destruição dos recursos naturais existentes. Já as unidades de uso sustentável possuem a finalidade de contribuir com a conservação da natureza com o uso sustentável de parte dos recursos naturais existentes (Brasil, 2000).

\section{Cenário conceitual e característico das unidades de conservação (UCs)}

As unidades de conservação são espaços ambientalmente restritos à conservação e à preservação dos recursos naturais, não passíveis de exploração para fins inteiramente econômicos e lucrativos. Compõem-se de vieses intocáveis e racionais, cuja praticidade é positivista com visão de futuro para melhoria da qualidade de vida.

As UCs constituem-se em áreas delimitadas no território às quais são atribuídos diversos graus de proteção, com a imposição de restrições à ocupação da terra e ao uso dos recursos naturais, visando à conservação da natureza, a manutenção e melhoria da qualidade ambiental, bem como o controle e a manutenção destes recursos para utilização futura (Gallo Junior e Olivato, 2005; Piedade, 2013). Para Oliveira (2014) as áreas especialmente protegidas no Brasil têm o objetivo de proteger belezas cênicas, preservar recursos hídricos, manejo de recursos naturais, desenvolvimento de pesquisas científicas, manutenção do equilíbrio climático e ecológico, preservação de recursos genéticos e proteger a biodiversidade.

Há uma série de espaços ambientalmente protegidos pelas normas ambientais nacionais. Assim como as Áreas de Preservação Permanente (APP's) e as Áreas de Reserva Legal (ARL), também as Unidades de Conservação (UCs) estão inseridas no status de espaço territorial especialmente protegido previsto no art. $225, \S 1$, inciso III, da Constituição Federal de 1988. Pode-se afirmar que "espaço territorial especialmente protegido" é gênero, onde "unidade de conservação" é espécie, ou seja, toda unidade de conservação é um espaço especialmente protegido, mas nem todo espaço especialmente protegido é uma unidade de conservação (Silva, 2016).

A criação destas áreas é um passo fundamental para a proteção da biodiversidade e para a manutenção da qualidade de vida do homem na terra, mas também representa um grande desafio que se coloca aos gestores públicos (Bezerra et al., 2018), pelo fato de estas exigirem uma série de regramentos para seu funcionamento. Neste contexto, entende-se por Sistema Nacional de Unidades de Conservação (SNUC) como sendo o conjunto organizado de áreas naturais protegidas que, planejado, manejado e gerenciado como um todo é capaz de viabilizar os objetivos nacionais de conservação (Milano, 1989). Afora isso, as unidades de conservação também se propõem a proteger as paisagens notáveis, contribuindo para a perpetuação das belezas cênicas naturais para as presentes e futuras gerações (Farias et al., 2016).

Cumpre destacar do conceito legal algumas importantes caraterísticas das Unidades de Conservação: 1. Espécie de espaço territorial protegido (inseridas no artigo 225, § 1ํ, inciso III, da Constituição Federal de 1988); 2. Atributos naturais relevantes (motivo de proteção pelas normas ambientais); 3. Legalmente instituídos (por decreto do

Rev. Bras. Gest. Amb. Sustent., 2020, vol. 7, n. 15, p. 211-223. 
chefe do poder executivo ou por lei formal); 4. Objetivos de conservação (e por isso são áreas ambientalmente protegidas); 5. Limites físicos definidos; 6. Regime especial de proteção e administração (Silva, 2016). Incumbe-se aos poderes públicos ou privados a competência de criá-los e mantê-los (Barros et al., 2012).

\title{
O Sistema Nacional do Meio Ambiente (SISNAMA) e os órgãos executores da Política Nacional do Meio Ambiente (PNMA)
}

O Sistema Nacional do Meio Ambiente mais comumente conhecido no âmbito jurídico ambiental como o SISNAMA do Ministério do Meio Ambiente trata-se de um conjunto de aparelhos ou entes da administração pública das esferas federal, estadual e municipal incumbidos a realizar atos protetivos em prol da melhoria da qualidade ambiental. De acordo com Rodrigues (2016) o Sistema Nacional do Meio Ambiente (SISNAMA) é integrado por todos os órgãos e entidades da União, dos Estados, do Distrito Federal, dos Territórios e dos Municípios, bem como as fundações instituídas pelo Poder Público, responsáveis pela proteção e melhoria da qualidade ambiental (art. 6ํㅡ, caput, da Lei $\mathrm{n}^{0}$ 6.938/1981), o que abarca, em numerus apertus, não só aqueles listados, expressamente, nos vários incisos, como também os que, por força de lei, recebem poderes de implementação ambiental, como o Ministério Público e as agências governamentais especializadas ou temáticas.

A exemplo do Sistema Nacional de Educação, do Sistema Nacional de Saúde e do Sistema Nacional de Trânsito trata-se de um sistema nacional administrativo desprovido de personalidade jurídica, cujas determinações são implementadas pelos órgãos e entidades que o integram (Farias et al., 2016). Os autores em relevo ainda relatam que o objetivo do Sistema Nacional de Meio Ambiente é promover e integrar a atuação dos órgãos ambientais em âmbito federal, estadual e municipal, fazendo com que as políticas públicas de meio ambiente sejam trabalhadas de forma harmônica e uniforme.

No Brasil, possivelmente em resposta às questões levantadas na Conferência de 1972, cria-se a Secretaria Especial do Meio Ambiente (SEMA), em 1973, vinculada ao Ministério do Interior e, em 1981, publica-se a Lei no 6.938/1981, da Política Nacional do Meio Ambiente (PNMA). Esta lei criou o Sistema Nacional de Meio Ambiente (SISNAMA), composto pelo Conselho Nacional de Meio Ambiente (CONAMA). No entanto, estes instrumentos só entraram em atividade em 1984 (Salheb, et al., 2009). Passados oito anos após a formalização da PNMA, foi criado em 1989 o Instituto Brasileiro do Meio Ambiente e dos Recursos Naturais Renováveis (IBAMA). A nova instituição alcançou um escopo muito mais abrangente do que as competências institucionais da SEMA, uma vez que assumiu as atribuições dos diversos órgãos, antes responsáveis pela execução da política ambiental de forma fragmentada (Ferreira e Salles, 2016), conforme podemos ver avante neste mesmo documento pelo qual Salheb et al. (2009) adverte,

\begin{abstract}
A Constituição Federal de 1988 inseriu os princípios do desenvolvimento sustentável em seu artigo 225. Em 1989, cria-se o Instituto Brasileiro de Meio Ambiente e dos Recursos Naturais Renováveis (IBAMA), reunindo nele as competências dos demais órgãos setoriais de meio ambiente extintos, como o Instituto Brasileiro de Desenvolvimento Florestal (IBDF), a Superintendência de Desenvolvimento da Borracha (SUDHEVEA), a Superintendência de Desenvolvimento da Pesca (SUDEPE) e a Secretária Especial do Meio Ambiente (SEMA) (Salheb, et al.,2009).
\end{abstract}

Com a criação do IBAMA pela Lei no 7.735/1989, em redação alterada pela Lei no 11.516/2007, que dispõe sobre a idealização do Instituto Chico Mendes de Conservação da Biodiversidade (ICMBio), elevou-se a qualidade de ambos os órgãos como executores da 
PNMA, sob a perspectiva de melhorias na proteção, fiscalização e controle dos recursos naturais, bem como em Unidades de Conservação (UCs) para minimização e mitigação dos danos provocados ao meio ambiente mediante execução de atividades antrópicas nestes recintos.

Hüller e Mello (2011) relatam que em 2007 foi criado o Instituto Chico Mendes de Conservação da Biodiversidade que é uma autarquia em regime especial criada pela Lei no 11.516/2007, a qual é vinculada ao Ministério do Meio Ambiente e integra o Sistema Nacional do Meio Ambiente (SISNAMA). Os mesmos autores supracitados antes ainda relatam que,

\begin{abstract}
Compete a este instituto executar as ações do Sistema Nacional de Unidades de Conservação, podendo propor, implantar, gerir, proteger, fiscalizar e monitorar as UCs instituídas pela União. Compete ainda a este órgão fomentar e executar programas de pesquisa, proteção, preservação e conservação da biodiversidade e exercer o poder de polícia ambiental para a proteção das Unidades de Conservação federais (Hüller e Mello, 2011).
\end{abstract}

\title{
Competências dos órgãos executores da Política Nacional do Meio Ambiente (PNMA) em unidades de conservação
}

É possível entender o SISNAMA como a mistura de abstração e concretude, pois permanece e atua na medida em que existem e atuam os órgãos que o constituem. Além disso, exerce poder de polícia administrativa ambiental, notadamente o IBAMA, o instituto Chico Mendes e os órgãos seccionais e locais, com autoridade para praticar atos tutelares que sejam necessários à gestão do meio ambiente (Furstenau-Togashi e Souza-Hacon, 2012; Oliveira, 2014). Nesta esteira, a referida normatização do SNUC - Lei 9.985/2000, conforme apontam Brasil (2000) e Rodrigues (2016) também apresenta a seguinte estrutura destinada à gestão do SNUC, sendo disciplinada pelo o art. 6은

O SNUC será gerido pelos seguintes órgãos, com as respectivas atribuições:

I - Órgão consultivo e deliberativo: o Conselho Nacional do Meio Ambiente Conama, com as atribuições de acompanhar a implementação do Sistema;

II - Órgão central: o Ministério do Meio Ambiente, com a finalidade de coordenar o Sistema; e

III - órgãos executores: o Instituto Chico Mendes e o Ibama, em caráter supletivo, os órgãos estaduais e municipais, com a função de implementar o SNUC, subsidiar as propostas de criação e administrar as unidades de conservação federais, estaduais e municipais, nas respectivas esferas de atuação (Brasil, 2007; Rodrigues 2016b).

Silva (2016) adverte que os entes federativos foram criados com a finalidade de estabelecer uma rede de agências governamentais, nos diversos níveis da federação, visando a assegurar mecanismos capazes de, eficientemente, implementar a Política Nacional do Meio Ambiente. Para Gallo Junior e Olivato (2005) o Instituto Brasileiro de Meio Ambiente e dos Recursos Naturais Renováveis (IBAMA) é o órgão executivo do Sistema, sendo responsável pela implementação e aplicação da Política, concentrando atribuições relativas à fiscalização e controle, bem como à administração das unidades de conservação em nível federal.

Em alguns casos, o IBAMA é demandado para fiscalizar UC por causa do disposto no ato (decreto ou lei) de criação da UC, que preceitua ser sua atribuição gerir a UC. Entretanto, quando os atos constitutivos da UC forem anteriores a 2007, data de criação do ICMBio, deve-se considerar esta autarquia, e não o Ibama, como o ente adequado para a 
fiscalização ambiental em Unidades de Conservação em âmbito Federal. A mera menção do IBAMA não tem mais efeitos após a criação do ICMBio (Bim, 2018). 0 Instituto Chico Mendes de Conservação da Biodiversidade foi criado pela Lei no 11.556/2007, em meio a uma polêmica, que teve como temática central o esvaziamento do IBAMA, o responsável anterior pela execução do SNUC. Instituído mediante Medida Provisória, o mencionado órgão nasce com a responsabilidade de gerenciar as unidades de conservação federais nos estados. Ele é mais uma estrutura dentro da burocracia estatal (Silva e Cunha, 2010).

Bim (2018) comenta que a compreensão da competência comum para a fiscalização ambiental afigura-se problemática não apenas porque o IBAMA tem entendimento firme de que não deve substituir os demais órgãos do Sistema Nacional do Meio Ambiente (SISNAMA) na atividade de fiscalização ambiental, sob pena de inviabilizar as suas metas estratégicas de combate ao desmatamento ou demais infrações ambientais, mas também porque ela distorce o modelo de competências concorrentes federativas, como é visto adiante.

O desmatamento e queimadas são atos infracionais de significativas proporções que afetam as unidades de conservação, os quais merecem atenção reciproca por parte dos órgãos de controle e fiscalização ambiental federais, estaduais e municipais. Em razão disso, a Lei Complementar no 140/2011, que dispõe sobre a cooperação entre a União, os Estados, o Distrito Federal e os Municípios nas ações administrativas decorrentes do exercício da competência comum relativas à proteção das paisagens naturais notáveis, à proteção do meio ambiente, ao combate à poluição em qualquer de suas formas e à preservação das florestas, da fauna e da flora; e altera a Lei no 6.938/1981 (Brasil, 2011), também define as ações de cooperação voltadas para as unidades de conservação de modo aparelhado.

A Lei Complementar no 140/2011 apresenta a definição de critérios para fixação da competência administrativa dos entes federativos no tocante ao licenciamento ambiental e a supressão de vegetação em unidades de conservação. Para estudos envolvendo esta temática o autor (Silva, 2016) constatou que fica evidente a prevalência do critério do ente federativo instituidor da unidade de conservação, ou seja, compete á (ao órgão ambiental da) União aprovar o manejo e a supressão de vegetação e/ou promover o licenciamento ambiental de empreendimentos e atividades localizadas ou desenvolvidas em unidades de conservação instituídas pela União. 0 mesmo critério se aplica aos demais entes administrativos estados e municípios consequentemente.

Ao encontro do Sistema Nacional de Unidades de Conservação da Natureza (SNUC) têm-se a Lei de Crimes Ambientais (Lei no 9.605/1998), que dispõe sobre as infrações e sanções administrativas ao meio ambiente e estabelece o processo administrativo federal para apuração destas infrações. A referida lei também versa sobre os crimes acometidos nestes recintos dentre os quais se destacam, o capítulo II, da aplicação da pena, art. 15, que expõe as circunstâncias que agravam a pena, quando não constituem ou qualificam o crime: e) atingindo áreas de unidades de conservação ou áreas sujeitas, por ato do Poder Público, a regime especial de uso (Brasil, 1998).

Nesta esteira o legislador do campo do Direito Ambiental menciona através do seu art. 10, caput, da referida Lei no $11.516 / 2007$, que fica criado o Instituto Chico Mendes de Conservação da Biodiversidade (ICMBio), autarquia federal dotada de personalidade jurídica de direito público, autonomia administrativa e financeira, vinculada ao Ministério do Meio Ambiente, com o propósito de:

I - Executar ações da política nacional de unidades de conservação da natureza, referentes às atribuições federais relativas à proposição, implantação, gestão, proteção, fiscalização e monitoramento das unidades de conservação instituídas pela União; 
II - Executar as políticas relativas ao uso sustentável dos recursos naturais renováveis e ao apoio ao extrativismo e às populações tradicionais nas unidades de conservação de uso sustentável instituídas pela União;

III - Fomentar e executar programas de pesquisa, proteção, preservação e conservação da biodiversidade e de educação ambiental;

IV - Exercer o poder de polícia ambiental para a proteção das unidades de conservação instituídas pela União; e

V - Promover e executar, em articulação com os demais órgãos e entidades envolvidos, programas recreacionais, de uso público e de ecoturismo nas unidades de conservação, onde estas atividades sejam permitidas (Brasil, 2007).

Trata-se de autarquia federal criada pela Lei no 11.516/2007 a partir de um fracionamento do IBAMA, sendo, portanto, autônoma administrativa e financeiramente vinculada ao Ministério do Meio Ambiente (Farias et al., 2016). No âmbito federal, o Ibama tem competência para licenciar e fiscalizar, ao passo que a atribuição do ICMBio é gerir e fiscalizar as UCs federais. A competência primária para a fiscalização ambiental nas áreas das UCs, bem como nas respectivas zonas de amortecimento (ZAs), pertence ao órgão gestor da UC (Bim, 2018).

A atinente Lei no 11.516/2007, através do seu art. 2o também destaca que fica criado o Instituto Brasileiro do Meio Ambiente e dos Recursos Naturais Renováveis IBAMA, autarquia federal dotada de personalidade jurídica de direito público, autonomia administrativa e financeira, vinculada ao Ministério do Meio Ambiente, com a finalidade de:

\footnotetext{
I - Exercer o poder de polícia ambiental;

II - Executar ações das políticas nacionais de meio ambiente, referentes às atribuições federais, relativas ao licenciamento ambiental, ao controle da qualidade ambiental, à autorização de uso dos recursos naturais e à fiscalização, monitoramento e controle ambiental, observadas as diretrizes emanadas do Ministério do Meio Ambiente; e
}

III - Executar as ações supletivas de competência da União, de conformidade com a legislação ambiental vigente (NR) (Brasil, 2007).

É neste sentido que se considera fundamental a efetiva gestão de uma unidade de conservação. 0 papel do estado é garantir que, uma vez criadas, elas tenham condições de serem implantadas (Bezerra et al., 2018). Apesar da fragmentação institucional de ambos os órgãos, se manteve na condição de perspectiva de trabalho do ICMBio e de setores expressivos do IBAMA, mostrando sua consistência teórico-metodológica e sua coesa perspectiva política, na luta por justiça ambiental e social no país (Loureiro e Saisse, 2014).

Criar áreas protegidas e programas de restauração ecológica são medidas necessárias para a melhor situação do ecossistema natural, com vistas a aumentar a conectividade da paisagem e os esforços de conservação cujo planejamento deve ser baseado na priorização de áreas com minimização dos processos de degradação dos ecossistemas naturais causados pelo crescimento urbano e agrícola (Mello et al., 2016).

\section{Considerações finais}

As unidades de conservação (UCs) são espaços ambientalmente protegidos de admirável significância para a preservação e conservação da biodiversidade, porém, carecem de regulamentos mais rígidos que endureçam os moldes que involucram a 
fiscalização e as punições aplicadas pelo IBAMA e ICMBio respectivamente em relação as ações antrópicas ilícitas e/ou crimes ambientais cometidos nesses ambientes. Faz-se imperativo o apoio de maneira ativa e participativa da sociedade civil e do poder público nas esferas federal, estadual e municipal para que ambos os entes fiscalizatórios atinjam os objetivos propostos pela política ambiental brasileira em prol da sustentabilidade ambiental.

O IBAMA e ICMBio exercem poder de polícia no que tange a fiscalização das unidades de conservação, porém os atos que direcionados a gestão condicionam-se tal competência ao Instituto Chico Mendes (ICMBio). É imprescindível a admissão e permanência de autonomia dos órgãos executores da Política Nacional do Meio Ambiente (PNMA), IBAMA e ICMBio, junto ao cumprimento de suas agilidades, ações e competências conforme estabelece a legislação ambiental pertinente em vigor.

A criação e permanência de Unidades de Conservação (UCs) ao longo do tempo pela legislação ambiental em alento e órgãos responsáveis pela sua formulação, se fazem mister para conservação e preservação da biodiversidade levando sempre em apreço o princípio in dubio pro natura ou in dubio pro ambiente, ou seja, nos acontecimentos em que não for oportuno uma explanação parecida ou anotação unívoca, a alternativa ou escolha deve incidir sobre a interpretação mais favorável ao meio ambiente suporte de todos os demais atributos condicionantes a sobrevivência humana.

\section{Agradecimentos}

A Fundação de Amparo a Ciência e Tecnologia do Estado de Pernambuco (FACEPE) pela bolsa estudo concedida ao primeiro autor deste trabalho, disponibilizada para o biênio 20192021.

\section{Conflito de interesses}

Os autores declaram não haver conflito de interesses.

\section{Referências}

Barros, D. A.; Borges, L. A. C.; Nascimento, G. O.; Pereira, J. A. A.; Rezende, J. L. P.; Silva, R. A. Breve análise dos instrumentos da política de gestão ambiental brasileira. Política \& Sociedade, v. 11 , n. 22 , p. 155-179, 2012. https://doi.org/10.5007/21757984.2012v11n22p155

Bezerra, G. S. C. L.; Carvalho, R. M. C. M. O.; Lyra, M. R. C. C.; Frutuoso, M. N. M. A.; Brandão, S. S. F. Política pública e o desafio da participação social na gestão de unidades de conservação. Holos, v. 6, p. 117-129, 2018. https://doi.org/10.15628/holos.2018.4486

Bim, E. F. Fiscalização ambiental à luz do princípio da subsidiariedade: contornos da competência comum. Revista de Informação Legislativa, v. 55, n. 217, p. 85-114, 2018. Disponível em: <https://www12.senado.leg.br/ril/edicoes/55/217/ril_v55_n217_ p85.pdf>. Acesso em: 01 jan. 2020.

Brasil. Constituição da República Federativa do Brasil de 1988. Disponível em: $<$ http://www.planalto.gov.br/ccivil_03/constituicao/constituicaocompilado.htm>. Acesso em: 01 jan. 2020. 
Brasil. Decreto no 1.922, de 5 de junho de 1996. Dispõe sobre o reconhecimento das Reservas Particulares do Patrimônio Natural, e dá outras providências. Disponível em: <http://www.planalto.gov.br/ccivil_03/decreto/Antigos/D1922.htm>. Acesso em: 01 jan. 2020.

Brasil. Decreto no 98.914, de 31 de janeiro de 1990. Dispõe sobre a instituição, no território nacional, de Reservas Particulares do Patrimônio Natural, por destinação do proprietário. Disponível em: <http://www.planalto.gov.br/ccivil_03/decreto/19901994/D98914.htm>. Acesso em: 01 jan. 2020.

Brasil. Lei Complementar no 140, de 8 de dezembro de 2011. Fixa normas, nos termos dos incisos III, VI e VII do caput e do parágrafo único do art. 23 da Constituição Federal, para a cooperação entre a União, os Estados, o Distrito Federal e os Municípios. Disponível em: <http://www.planalto.gov.br/ccivil_03/LEIS/LCP/Lcp140.htm>. Acesso em: 01 jan. 2020 .

Brasil. Lei no 6.938, de 31, de agosto de 1981. Institui a Política Nacional de Meio Ambiente - PNMA e dá outras providências. Disponível em: <http://www.planalto.gov.br/ccivil_03/LEIS/L6938.htm>. Acesso em: 01 jan. 2020.

Brasil. Lei no 7.735, de 22 de fevereiro de 1989. Dispõe sobre a extinção de órgão e entidade autárquica, cria o Instituto Brasileiro de Meio Ambiente e Recursos Naturais Renováveis e dá outras providências. Disponível em: <http://www.planalto.gov.br/ ccivil_03/LEIS/L7735.htm>. Acesso em: 01 jan. 2020.

Brasil. Lei no 9.605, de 12 de fevereiro de 1998. Dispõe sobre as sanções penais e administrativas derivadas de condutas e atividades lesivas ao meio ambiente, e dá outras providências. Disponível em: <http://www.planalto.gov.br/ccivil_03/leis/19605.htm>. Acesso em: 01 jan. 2020.

Brasil. Lei no 9.985, de 18 de julho 2000. Institui o Sistema Nacional de unidades de Conservação da Natureza-SNUC e dá outras providências. Disponível em: <http://www.planalto.gov.br/ccivil_03/leis/L9985.htm>. Acesso em: 01 jan. 2020.

Brasil. Lei no 11.516, de 28 de agosto de 2007. Dispõe sobre a criação do Instituto Chico Mendes de Conservação da Biodiversidade - Instituto Chico Mendes. Disponível em: $<$ http://www.planalto.gov.br/ccivil_03/_Ato2007-2010/2007/Lei/L11516.htm>. Acesso em: 01 jan. 2020.

Chizzotti, A. A pesquisa qualitativa em ciências humanas e sociais: evolução e desafios. Revista Portuguesa de Educação, v. 16, n. 2, p. 221-236, 2003.

Coutinho, F. S. N. Os espaços territoriais especialmente protegidos e as zonas de proteção no direito ambiental brasileiro. In: Benjamin, A. H. (Org.). Paisagem, natureza e Direito. São Paulo: Imprensa Oficial, 2005.

Farias, T.; Coutinho, F. S. N.; Melo, G. K. R. M. M. Sinopse para concursos: Direito Ambiental. 4. ed. ver., amp. e atual. Salvador: Juspodivm, 2016.

Ferreira, M. B. M.; Salles, A. O. T. Política ambiental brasileira: análise histórico-constitucionalista das principais abordagens estratégicas. Revista de Economia, v. 42, n. 2, 2016. https://doi.org/10.5380/re.v42i2.54001

Franco, J. L. A.; Schittini, G. M.; Braz, V. S. História da conservação da natureza e das áreas protegidas: panorama geral. Revista Historiæ, v. 6, n. 2, p. 233-270, 2015.

Furstenau-Togashi, H.; Souza-Hacon, V. A evolução do debate socioambiental no Brasil: legislação, etnoconservação e racionalidade ambiental. Economía, Sociedad y Territorio, v. 12 , n. 39, p. 403-424, 2012.

Rev. Bras. Gest. Amb. Sustent., 2020, vol. 7, n. 15, p. 211-223. 
Gallo Junior, H.; Olivato, D. Unidades de conservação e política ambiental no Brasil. Anais do X Encontro de Geógrafos da América Latina, Universidade de São Paulo, 2005. Disponível em: <http://observatoriogeograficoamericalatina.org.mx/egal10/Geografia socioeconomica/Geografiapolitica/12.pdf>. Acesso em: 01 jan. 2020.

Hüller, C. R.; Mello, N. A. Gestão privada de unidades de conservação: as reservas particulares do patrimônio natural. Syner Gismus Scyentifica UTFPR, v. 6, n. 1, 2011. Disponível em: <http://revistas.utfpr.edu.br/pb/index.php/SysScy/article/viewFile/ 1236/839>. Acesso em: 01 jan. 2020.

Loureiro, C. F. B.; Saisse, M. Educação ambiental na gestão ambiental pública brasileira: uma análise da SEMA ao ICMBio. Revista de Educação Pública, v. 23, n. 52, p. 105-129, 2014. https://doi.org/10.29286/rep.v23i52.1427

Madruga Filho, V. J. P.; Fernandes, H. F.; Silva, J. R. S. Direito Internacional Ambiental e sua interface no contexto constitucional brasileiro. Revista Brasileira de Gestão Ambiental e Sustentabilidade, v. 5, n. 10, p. 517-526. 2018. https://doi.org/10.21438/rbgas.051007

Mello, K.; Toppa, R. H.; Cardoso-Leite, E. Priority areas for forest conservation in an urban landscape at the transition between Atlantic Forest and Cerrado. CERNE, v. 22, n. 3, p. 277288, 2016. https://doi.org/10.1590/01047760201622032172

Menezes, K. W. S. Análise da capacidade de suporte em áreas protegidas: a Área de Proteção Ambiental do Estuário do Rio Ceará e o Parque Botânico do Ceará, Fortaleza/CE. Planeta Amazônia: Revista Internacional de Direito Ambiental e Políticas Públicas, n. 10, p. 23-34, 2018. https://doi.org/10.18468/planetaamazonia.2018n10.p23-34

Milano, M. S. Unidades de conservação: conceitos e princípios de planejamento e gestão. Curitiba, FUPEF, 1989.

Milano, M. S.; Bernardes. A. T.; Ferreira, L. M. Possibilidades alternativas para o manejo e o gerenciamento das unidades de conservação. Brasília: IBAMA, 1993.

Oliveira, C. R. A importância das unidades de conservação para a preservação de um meio ambiente equilibrado. Rio Grande: Universidade Federal do Rio Grande, 2014. (Monografia de graduação).

Orzechowsk, A.; Liesenberg, V. Relação entre unidades de conservação e a legislação ambiental brasileira: um estudo de caso na Região Sul. Geosul, v. 24, n. 48, p. 131-152, 2009. https://doi.org/10.5007/2177-5230.2009v24n48p131

Piedade, F. O. Legislação ambiental e a gestão de unidades de conservação no Maranhão. Revista Direito Ambiental e Sociedade, n. 2, v. 3, p. 175-189, 2013.

Rodrigues, M. A. Direito ambiental esquematizado. 3. ed. São Paulo: Saraiva, 2016.

Rodrigues, T. C. S.; Viegas, J. C.; Feitosa, A. C. Impactos ambientais decorrentes do uso e ocupação do solo, na comunidade Negra Jamary dos Pretos, Turiaçu - Maranhão. Anais do I Encontro Ibero-Americano de Geomorfologia e VIII Simpósio Nacional de Geomorfologia, 2010.

Salheb, G. J. M.; Peres Neto, H. A. P.; Oliveira, I. M.; Amaral Júnior, M. F.; Boettger, R. J. C. S.; Monteiro, V. C. S.; Superti, E. Políticas públicas e meio ambiente: reflexões preliminares. Planeta Amazônia: Revista Internacional de Direito Ambiental e Políticas Públicas, v. 1, p. 5-26, 2009.

Silva, J. I. A. O.; Cunha, L. H. Regime jurídico das unidades de conservação: suas características jurídico-ambientais. Revista Dataveni@, v.2, n. 1, p. 121-143, 2010. 
Silva, R. F. T. Manual de Direito Ambiental. 5. ed. rev. e atual. 2015.

Tuan, Y.-F. Tipofilia: um estudo a percepção, atitudes e valores do meio ambiente. Londrina: Eduel, 2012. 